\title{
Solving Structures of Nano-precipitates in Minerals Using TEM Imaging and Single-crystal XRD Diffraction Methods
}

\section{Huifang Xu}

\section{University of Wisconsin-Madison, Madison, Wisconsin, United States}

Nano-precipitates in host minerals can provide information about their formation environment and evolution history. Because both composition and structure of the nano-precipitates are related to their host phases, it is possible to determine their crystal structures using atomic resolution imaging and singlecrystal diffraction from both host phase and precipitates. For simple composition system like pyrrhotite ( $\mathrm{Fe}_{1-\mathrm{x}} \mathrm{S}$ ), structure of a monoclinic $\alpha-\mathrm{Fe}_{3} \mathrm{~S}_{4}$ nano-precipitate can be determined directly based on its $\mathrm{Z}$ contrast images. The nano-precipitates with large magnetic coesivity may cause magnetic property change of the pyrrhotite. Si in some magnetite occurs as Si-magnetite nano-precipitates. The nano-phase with unique stoichiometry $\left(\gamma-\mathrm{Fe}_{1.5} \mathrm{SiO}_{4}\right)$ is a silicate spinel similar to a high-pressure mineral ringwoodite. The ferric iron dominated silicate spinel may be called as "ferri-ringwoodite." Its monoclinic polymorph is laihunite-1M. Na-bearing adularia (hydrothermal K-feldspar) displays diffuse reflections that violate $C$ centered Bravais lattice. TEM image shows needle-like nano-precipitates along $c$-axis. Its SAED pattern shows diffuse reflections violate $C$-centering (Fig. 1). Due to high density of the nano-precipitates $(\sim 20$ $\%$ ), it is possible to refine the structure of the host phase (orthoclase) with $C 2 / \mathrm{m}$ symmetry and the nanoprecipitates with $\mathrm{Pa}$ symmetry using single-crystal XRD method for the 2-phase system [1]. Previously reported $P 21 / a$ symmetry was resulted from an artifact of overlapped diffraction spots from the nanoprecipitates $(\mathrm{Pa})$ and host orthoclase $(\mathrm{C} 2 / \mathrm{m})$. Adularia, orthoclase and microcline with the $\mathrm{Pa}$ nanoprecipitates indicate very slow cooling of their host rocks at low temperature. Similar phenomenon occurs in laihunite system with the laihunite-3Or nano-phase in the laihunite-1M host (Fig. 2). The laihunte-3Or structure $\left[\mathrm{Fe}(\mathrm{II})_{3} \mathrm{Fe}(\mathrm{III})_{2}\left(\mathrm{SiO}_{4}\right)_{3}\right]$ can be considered as 2 laihunite-1M [ $\left.\mathrm{Fe}(\mathrm{II})_{0.5} \mathrm{Fe}(\mathrm{III})_{1} \mathrm{SiO}_{4}\right]$ layers in twin relationship with a fayalite-layer $\left(\mathrm{Fe}(\mathrm{II})_{2} \mathrm{SiO}_{4}\right)$ as the twin boundary [2]. The laihunite-3Or will be orthorhombic. Previously reported monoclinic 3-layer "laihinute-3M" was resulted from an artifact of overlapped diffraction spots from the nano-precipitates of laihunite-3Or $(P b n m)$ and laihinite-1M $\left(P 2{ }_{1} / n\right)$. The structural intergrowth of 3-layer laihunite and 1-layer laihunite will results in chemical compositions that lie between the ideal 1-layer laihunite and 3-layer laihunite, such as the reported chemical formula of [] $0.4 \mathrm{Fe}(\mathrm{II})_{0.8} \mathrm{Fe}(\mathrm{III})_{0.8} \mathrm{SiO}_{4}$ reported by Shen et al. (1984) [3]. The challenge for the XRD method is to get accurate intensities of the diffuse reflections. Inaccurate intensities form the diffuse reflections may cause certain unreasonable bond distances.
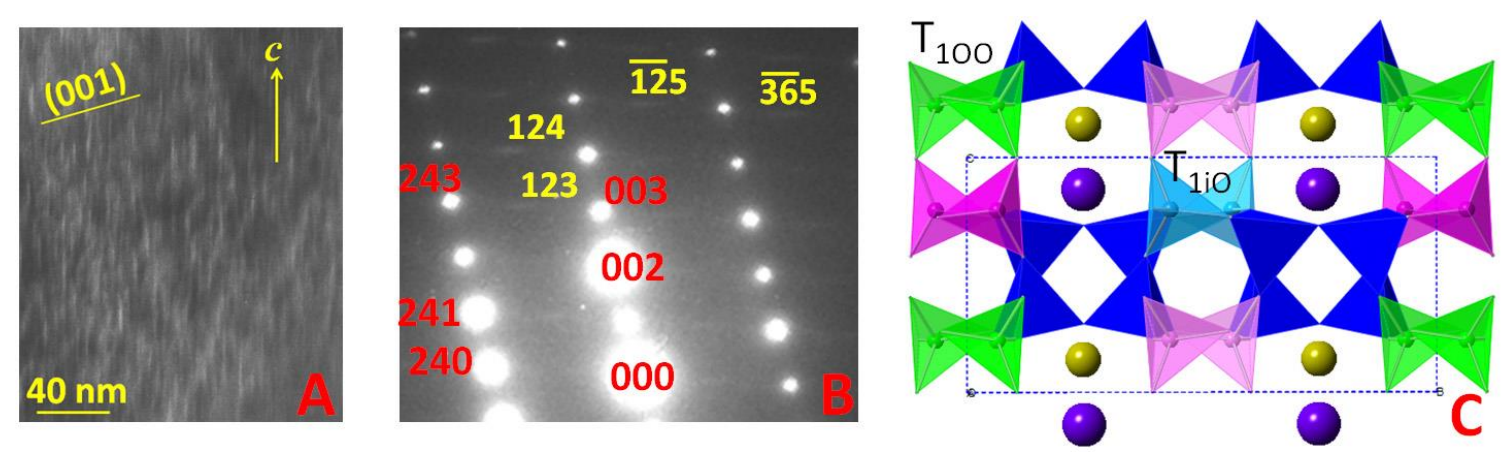
Figure 1. DF image (A) and SAED pattern (B) showing nano-precipitates and streaking reflections from the nano-phase. Structure model (C) from single crystal XRD illustrates ordered K-Na distributions.
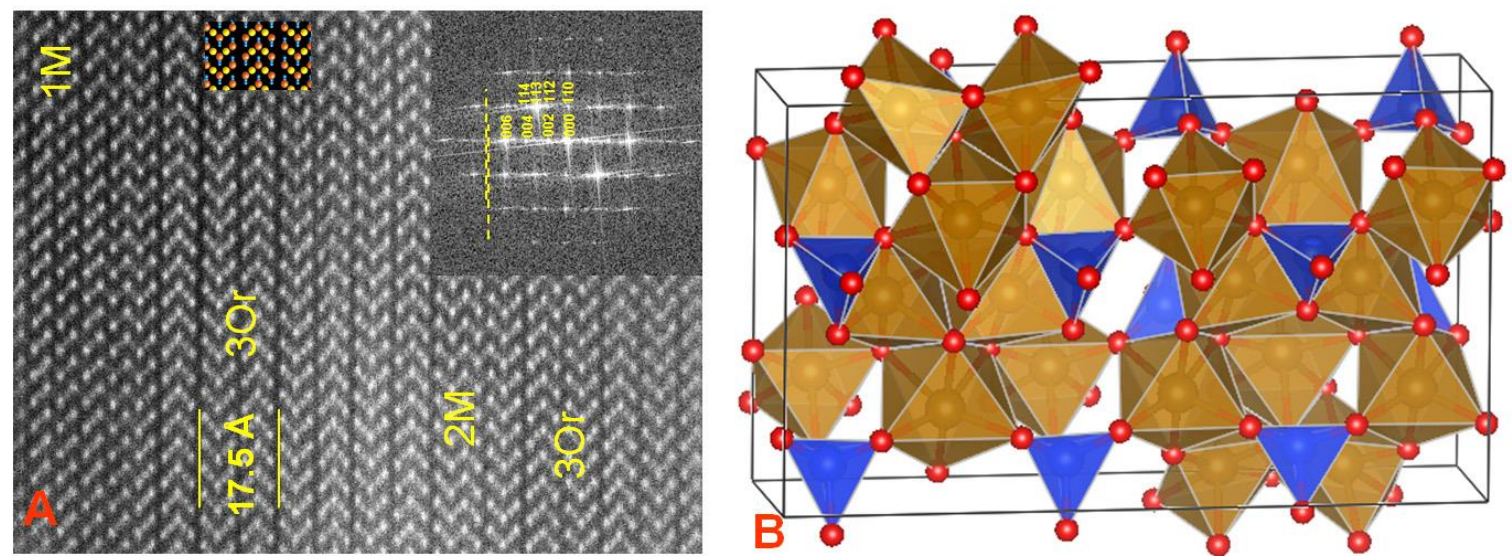

Figure 2. Z-contrast image (A) showing domains of laihunite-1M [Fe(II)0.5Fe(III)1SiO4] and laihunite3Or domains. Structure model (B) for the laihunite-3Or [Fe(II)3Fe(III)2(SiO4)3] nano-phase from singlecrystal XRD refinement.

\section{References}

[1] $\mathrm{Xu}, \mathrm{H}$. et al. (2020) Nano-phase $\mathrm{KNa}\left(\mathrm{Si}_{6} \mathrm{Al}_{2}\right) \mathrm{O}_{16}$ in adularia: A new member in the alkali feldspar series with ordered K-Na distribution. Minerals 2019, 9, 649; doi:10.3390/min9110649.

[2] Xu, H. et al. (2014) Crystal structures of laihunite and intermediate phases between laihunite-1M and fayalite: Z-contrast imaging and ab initio study. American Mineralogist, 99, 881-889.

[3] Shen, B. et al. (1984) Superstructure of laihunite-3M. American Mineralogist, 71, 1455-1460. 